\title{
Nonverbal Immediacy in Teaching Process: A Case Study in Secondary Education
}

\author{
Panagiotis J. Stamatis and Vasiliki E. Kostoula
}

\section{ABSTRACT}

\begin{abstract}
Communication holds a leading position in education and more specifically in the learning process. Especially the communication which takes place between teacher and student is one of the most important skills in education. If teaching communication is well established, pedagogical relationships are promoted and a positive pedagogical environment is created. Within this framework this article aims at pointing out the positive impact of the teacher's nonverbal immediacy in the teaching and learning processes. Teaching immediacy is a powerful learning incentive and renders the learning process more efficient. The results of a case study examining nonverbal immediacy of the secondary education teachers of an Upper Secondary General Education School (Lyceum) are presented.
\end{abstract}

Keywords: nonverbal communication, teaching communication, teaching immediacy

\section{INTRODUCTION}

\section{A. Communication-Teaching Communication}

Educational practice is predominantly communicative. Pedagogical interactions developed every day at school, and more specifically in the classroom, are part of the instructional communication process. The creation of a pedagogical environment and warn interpersonal relationships are elements that reinforce teaching and learning efficiency. The two basic partners of the education process, teacher and student, develop human relationships based on verbal and nonverbal communication.

Modern teachers care for the development of a communication learning framework and the improvement of its communication adequacy. In this way, teachers create a positive pedagogical environment and promote interhuman communication. Teaching immediacy and communication behavior of teachers can have a positive impact on learning outcomes. It is therefore considered necessary to determine the communication impact on the teaching practice.

Firstly, it is important to clarify the term "communication". Communication is a continuous, dynamic and constantly changing process (Stamatis, 2015). Through it, humans express who they are, communicate their thoughts and feelings (Fujishin, 2009). It causes actions and reactions, as it is a two-way process. Feedback, response is essentially what renders communication efficient (Garcia, 2012).

Communication is distinguished between verbal and nonverbal. Verbal communication is defined as an agreed
Published Online: January 10, 2021

ISSN: $2736-4534$

DOI : $10.24018 /$ ejedu.2021.2.1.25

Panagiotis J. Stamatis*

Department of Sciences of Preschool Education and Educational Design, University of the Aegean, Greece.

(e-mail: stamatis@ rhodes.aegean.gr) Vasiliki E. Kostoula

Department of Sciences of Preschool Education and Educational Design,

University of the Aegean, Greece.

(e-mail: kostvaso@gmail.com)

*Corresponding Author system of symbols used to share meaning. By the term symbols we mean arbitrary representations of thoughts, ideas, feelings, objects or actions used to code and decode a message (Johnston et al., 2017).

Nonverbal communication plays an important role in interpersonal communication. It sends out and receives messages in various ways without using verbal codes (Mutongi, 2017). Nonverbal communication takes place each time an individual affects another one through facial expressions, tone of voice or another communication channel. This type of communication may be intentional or not (Argyle, 2013).

In the teaching process three main factors play a part: transmitter, messages and receiver. The teacher sends his/her messages to the students, who are the recipients of the message. Then students respond to the teacher's messages by sending a new one to the teacher, who becomes a recipient in his/her turn. The communication process within the framework of a classroom is implemented through verbal and nonverbal communication (Bambaeeroo \& Shokrpour, 2017).

According to Klinzing and Aloisio (2014:219), "the ability of interactants to accurately decode what has been communicated is linked to the success of communication, as is the ability to bring out the full meaning of thoughts, intents, and affect through appropriate expressions". The expression of nonverbal sensitivity during the process contributes to the development of interpersonal relationships. The highly developed skill to code and decode messages and the correct 
choice of the appropriate communication channel is charisma. This is linked to a person's communication characteristics rather than to other variables. Charismatic people, having the ability to develop nonverbal communication, are more attractive and reliable when one first meets them; they are thus liked and more easily accepted by others. They make a striking impression through their nonverbal behavior, by being "silent".

Teaching communication, which is studied in this paper, focuses on ways of utilization of communication principles and methods in the teaching process and teachers' communication skills. It stresses the important role of communication in the learning process. It is useful for teachers to have communication skills in order to be more efficient in the classroom. It is not enough to know the subject taught; the subject needs to be pedagogically transmitted to students, so as to attract their attention and achieve learning outcomes. It is important for each teacher to integrate communication "techniques" in the teaching practice, such as discussion, pedagogical environment, and immediacy. The teaching efficiency of teachers is ensured by the teaching interest, the teacher's reliability, teaching clarity and teaching immediacy (Stamatis, 2014).

\section{B. Nonverbal Communication in the Education Process}

Teaching and learning are communication processes. Nonverbal communication within the framework of teaching falls into the study field of communication and examines the interaction relationships developed among the members of a school class. Communication and interaction between teacher and students affects teaching and learning. Interpersonal and interactive dimensions of school teaching are an important element for students' progress. However, although the nonverbal aspect of teaching is very important, it is usually marginal in the classroom. This communication concerns the interaction taking place when the involved parties get in touch (Christakis \& Chalatsis, 2014).

Nonverbal communication takes place through a group of messages that are not expressed with words and can be decoded, creating meaning that can accompany, contradict, replace, complement or stress the verbal message (Dobrescu \& Lupu, 2015). Information originating from nonverbal communication channels is revealing, more sincere and reliable, especially when verbal and nonverbal messages are contradictory (Malikiosi \& Sponta, 2002). Teachers who correctly decode students' nonverbal behavior may improve communication and create a positive pedagogical environment in class (Vrettos, 2010).

According to Okon (2011), nonverbal behavior during the teaching process seems to affect the communication process. The use of nonverbal messages on behalf of teachers, such as facial expressions, eye contact, gestures and body language in general is frequent. This shows their expectation to have an important impact on the students' behavior. Teaching immediacy and teachers' enthusiasm relate to positive results in the learning process.

\section{Teaching Immediacy}

In the field of education, the concept of immediacy is a factor related to the teaching attitude and communication behavior of teachers. Within this framework, literature refers to teacher or teaching immediacy (Stamatis, 2014).
Immediacy is defined by Richmond (2002:68, ref. in Sheybani, 2019) as the "degree of perceived physical or psychological closeness between people". Actually, it is a communication behavior including verbal and nonverbal communication elements. Verbal immediacy refers to stylistic differences in expression, based on which conclusions are drawn as to what is liked and what not. This refers to verbal expressions used by teachers. For example, a teacher could use the expression "our class" and not "my class" (Velez \& Cano, 2012). Verbal immediacy includes also verbal messages expressing empathy, transparency, kindness, reward, praise, feeling of inclusion, humor, personal knowledge and teachers' willingness to involve students in communication (Pladevall-Ballester, 2015).

Nonverbal teaching immediacy is defined as the behavior that reinforces proximity and nonverbal interaction between the communication parties. It is teachers' ability to transmit feelings, warmth, proximity, sense of belonging (Velez \& Cano, 2012). This can be achieved through eye contact, body position and movements, gestures, smile, expressiveness, haptics (Zhang \& Sapp, 2008).

Immediacy is a communication tool with a great value possessed by teachers. Teaching immediacy of teachers provides an important learning incentive for students. McCroskey, Richmond, \& Bennett (2006) hold that the views of students about the teachers' communication behavior and their nonverbal immediacy are linked to learning outcomes. Especially when teachers communicate information clearly, are characterized by nonverbal immediacy and respond responsibly, students are highly motivated to learn.

The importance of teaching immediacy is highlighted also by Richmond, McCroskey, \& Hickson (2012). According to them, teachers with high teaching immediacy increase students' motivation, creating a positive impact on the learning process. Moreover, they observe that students show less resistance to the teacher's effort to change their behavior. Teacher immediacy increases teacher and student communication and interaction, leading to the easy acquisition of information needed by students. They also ascertain that status difference between students and teachers is reduced, although they do not become equal. As a result, the student is encourage to ask questions about the subject without fear. Personal discussion reinforces pedagogical environment and this in turn creates a positive impact on the learning process.

In addition, Biçki (2008) points out that immediacy in teachers' behavior during teaching communication relates to a positive impact as well as to increased cognitive learning and more positive assessment of students made by teachers. In addition, it encourages students' positive attitude towards teachers and school. Immediacy therefore affects the learning process and atmosphere in class.

\section{PURPOSE OF RESEARCH}

Nonverbal communication and more specifically teaching immediacy affects significantly the teaching efficiency and creates a positive environment. Based on these elements, this survey aims at studying and interpreting the nonverbal behavior within the framework of the teaching and learning processes, as this is developed in an Upper Secondary General Education school (Lyceum) in Greece. The aim of 
this paper is to study in a microscale the teaching immediacy of secondary education teachers and its impact on the teaching process.

\section{SAMPLE}

To meet the research purpose, it was decided to take the teachers of an Upper Secondary General Education School (Lyceum) as a sample, in order to study their teaching immediacy within the framework of instructional communication. The reference sample consisted of the teachers of an education unit. Of them, $48.1 \%$ were men and $51.9 \%$ were women. The research preserved the anonymity of participants. The sample consists of teachers of various school subjects. The field research was conducted in MayJune 2019.

Sample teachers are employed teaches in an Upper secondary general school (Lyceum) in the periphery of Greece. The said school unit cooperated willingly and the teachers, several of whom have been working for several years in the said school unit, responded immediately to the survey questionnaire. In addition, it is a school with a positive environment and good student performance.

\section{METHOD}

This research is a case study and aims at providing evidence about the impact of nonverbal immediacy on teaching and learning processes. The standardized questionnaire was selected as methodological tool. With this type of questionnaire, information, attitudes, views, behaviors of the teachers of the said school unit can be collected in a clearer way. One of the advantages is that it has been tested and gives the possibility of comparison with previous research data. This renders it valid. In this way, accuracy and reliability is ensured in the research results. More specifically, respondents were given a self-assessment scale, Nonverbal Immediacy Scale-Self Report (NIS-S), by Richmond, McCroskey and Johnson (2003 ref. in Stamatis, 2014:348-349).

The questionnaire includes twenty-six closed-ended questions rated with a five point Likert scale. Each respondent had the possibility to choose only one option from the scale to state his/her view about nonverbal immediacy manifesting during his/her teaching. In this way he/she assesses his/her gestures, the level of proximity to the student, the eye contact made with students, his/her body position and his/her use of voice. The calculation of results (scoring) shows the indicator of self-assessment of nonverbal immediacy, which varies according to gender.

\begin{tabular}{|c|c|c|}
\hline Women & Mean $=102.0$ & S.D $=10.9$ \\
\hline \multicolumn{3}{|c|}{$\begin{array}{c}\text { Moderate immediacy: 93-111 } \\
\text { Low immediacy }=<92\end{array}$} \\
\hline Men & Mean $=93.8$ & S.D $=10.8$ \\
\hline \multicolumn{3}{|c|}{$\begin{array}{c}\text { High immediacy }=>104 \\
\text { Moderate immediacy: } 84-103 \\
\text { Low immediacy }=<83\end{array}$} \\
\hline
\end{tabular}

Fig. 1. Male/female nonverbal immediacy score.

\section{RESULTS}

The survey results about the indicators of nonverbal immediacy do not show a major divergence from international standards. It is ascertained that the nonverbal immediacy indicator is marginally close to the average indicator, as the total average is 93.46 (> 93.8). Regarding women, the nonverbal indicator is situated in the average indicator 102.29 (> 102.0). Sample women appear to be more immediate compared to male teachers. However, the results show that both men and women show moderate nonverbal immediacy.

More specifically as shown by the statistical processing of the specific indicators of self-assessment scale NIS-S, teachers during the teaching process stated that they often (Average - A.: 4.04, Standard deviation - S.D.: 0.89) move their hands while teaching. They rarely (A.: 2.2, S.D..: 0.80) appear to touch their students' hands or shoulders in the Lyceum classroom. In addition, they state that they rarely or occasionally (A.: 2.48, S.D.: 1.39) take distance from their students when students try to touch them. Teachers themselves often (A.: 3.81, S.D.: 1.27) avoid touching their students as they talk to them. Moreover, they rarely speak in a monotonous and boring way (A.: 1.93, S.D.: 0.78), they consider that their voice is pleasant for students to hear and rarely boring (A.: 1.96, S.D.: 0.80). They even often (A.: 4.19, S.D.: 0.68) or occasionally (A.: 4.33, S.D.: 0.62) color their voice. Regarding eye contact they state that they almost never avoid looking at their students (A.: 1.48, S.D.: 0.70), while, on the contrary, they often (A.: 4.44, S.D.: 0.69) look their students in the eye. The largest part of the sample state that they often or very often (A.:4.59, S.D.: 0.57) maintain eye contact with students. While teaching they state that they often feel their body relaxed (A.: 3.67, S.D.: 1.14) and occasionally (A.: 3.04, S.D.: 1.09) they feel tension and alertness. They are rarely (A.: 2.19, S.D.: 0.83) contracted. According to their statements, sample teachers often (A.: 4.11, S.D.: 0.80) sit or stand next to their students and often (A.: 4.22, S.D.: 0.75) approach their students and rarely or almost never (A.: 1.81, S.D.: 0.87) avoid doing so. Occasionally (A.: 3.19, S.D.: 1.14) they even lean their body towards their students as they speak and rarely to occasionally (A.: 2.59, S.D.: 1.18) avoid doing so. In addition, they state that they often (A.: 3.85, S.D.: 0.94) make grimaces, rarely (A.: 2.30, S.D.: 1.13) avoid them and often are expressive (A.: 4.26, S.D.: 0.81). In addition, they state that occasionally (A.: 3.37, S.D.: 0.88) their facial expression is calm. The sample teachers also state that they often (A.: 4.07, S.D.: 0.73) smile to their students.

\section{DISCUSSION}

Instructional communication is of great importance and internationally recognized (Simonds \& Cooper, 2011). Numerous studies have examined factors that may affect interaction taking place between teachers and students. More specifically, Staton (1989) makes a distinction between the study of instructional communication and the study of communication education, a notion which refers to issues broadly linked with the "educational dimension" of communication (Iordanidou, Stamatis, \& Valsamidou, 2020). Nussbaum and Friedrich (2005) explain that the study of 
instructional communication differs from the study of developmental communication. Friedrich (1989) studies the practical nature of the conduct of instructional communication research. In addition, Staton-Spicer and Wulff (1984) and Waldeck, Kearney and Plax (2001) used the method of content analysis to study research that has been conducted in the field of teaching communication. Beebe and Mottet (2009) introduce the theoretical perspectives in the study of teaching communication and review the methods used by researchers in this field. Instructional communication as a factor of a successful teaching and learning process has been further stressed by many studies. For this reason, studies reinforcing the efforts are important for the improvement of the teaching and learning process (Meyers, 2017).

The analysis of the research data of this study shows that respondents express often nonverbal immediacy by moving their hands (A.: 4.04) while teaching. In addition, teachers seem that they often (A.:4.22) stand close to their students during the teaching process. Based on literature, teachers who, while teaching, move among their students are perceived as more friendly and efficient (Vrettos, 2010).

Sample teachers avoid to touch their students to avoid misunderstandings. Teachers seem to stand close to their students (A.: 4.22) while teaching; this could also be considered as an indirect way of supervising and controlling students. The majority of teachers consider they color their voice (A.: 4.19). Regarding eye contact, the majority of the reference sample states that they maintain eye contact with students (A.: 4.59). Eye contact is particularly important for the school atmosphere, as the teacher may pretend to ignore a behavior or attitude or make eye contact to stress it.

Research results show that the nonverbal immediacy indicator is at moderate level, with women taking a slight lead over men. Given the Mediterranean culture of the sample, a higher nonverbal immediacy indicator would be expected. This may be due to the variety of specializations of teachers; not all of them take sufficient courses of Psychology and Pedagogy at university. Moreover, apart from the necessary training, a dissuasive culture has prevailed in Greek secondary education regarding the development of nonverbal immediacy behaviors. They are considered as incompatible with the obgectives and teaching methodology of school units (Stamatis, 2014).

\section{CONCLUDING STATEMENTS}

The processing of the research results reveals indicative trends about nonverbal immediacy of secondary education teachers of an Upper secondary general education school (Lyceum). The main goal set by this paper was to examine the contribution of teaching immediacy to the learning and teaching processes provided by the mentioned teachers. According to theory, teaching immediacy has a strong positive impact on learning outcomes (Mottet et al., 2006). It increases motivation in learning process and may modify students' behavior. Teachers with immediacy are considered more communicative and can manage their class. Moreover, this nonverbal skill may render teachers and students happier and more efficient in the teaching process (Richmond, McCroskey, \& Hickson, 2012).

The approach of the aforementioned research goal justified the choice of the rated scale Nonverbal Immediacy Scale, Self-Report (NIS-S) by Richmond, McCroskey and Johnson (2003), which was selected as the most appropriate one for the purposes of this study. The research results have shown the nonverbal immediacy of sample teachers during the performance of their teaching tasks. This specific sample of teachers' state behaviors referring to moderate level nonverbal immediacy. Taking into account that, due to the nature of their work, teachers develop dialogue and constantly interact with teenagers, this finding is considered as sufficiently justified, although nonverbal immediacy would have been expected to appear higher. One additional factor affecting nonverbal immediacy is the exam-oriented system. Students barricade themselves against their teacher, whom they view as assessor. This examiner-examinee relationship is a limiting factor in the development of interpersonal communication and therefore expression of nonverbal immediacy.

\section{SUGGESTIONS}

Based on this paper, communication is judged as an important priority in the field of education. Communication and in particular nonverbal skills may constitute the object of teachers' further training. In this way, interpersonal relationships between students and teachers will improve. In addition, it would be a good idea to include them in the teaching material and special guidelines to teachers, which would focus on issues of developing communication skills with a particular focus on nonverbal communication and related issues, such as teaching immediacy etc.

\section{LIMITATIONS AND WEAKNESS}

During the survey conduct, some limitations have to be taken into account, as it is a case study. Therefore, the sample is limited and does not allow for deductive statistics and generalization of results to a greater extent (Cohen, Manion, \& Morrison, 2007). In addition, there are difficulties in measuring the nonverbal communication behavior, despite the availability of measurement scales. The scale used demonstrates only the main characteristics of a behavior and not details it might hide. For these reasons, the results of this survey are not expected to be generally applicable, but refer to the sample teachers and show only indicative trends with similar features as the focus group of the sample.

\section{ACKNOWLEDGMENTS}

Heartfelt acknowledgments to the participants in the present case study who shared with us, the researchers, their inner thoughts and personal emotions developed during teaching process.

\section{REFERENCES}

M. Argyle, Bodily communication, $2^{\text {nd }}$ ed. London: Routledge, 2013.

F. Bambaeeroo, \& N. Shokrpour, "The impact of the teachers' nonverbal communication on success in teaching". Journal of Advances in Medical Education \& Professionalism, vol. 5(2), pp. 51-59, 2017.

A. Biçki, "An Observation of Nonverbal Immediacy Behaviours of Native and Non-native Lecturers". Journal of Social Sciences, vol. 5(1), pp. 120, 2008.

N. Christakis, \& P. Chalatsis, "Nonverbal communication, teaching practice and life in classroom", in Nonverbal Communication in Education 
Theory and practice, H. G. Klinzing, N. Polemikos, A. Kontakos, \& P. Stamatis (Eds.), Athens: Diadrasi, 2014, pp. 87-110.

L. M. Cohen, L. Manion, \& K. Morrison, Research Methods in Education (Translation by S. Kyranakis, M. Mavraki, Ch. Mitsopoulou, P. Bithara, M. Philopoulou) Athens: Metaichmio, 2007.

T. Dobrescu, \& G. Lupu, "The Role of Nonverbal Communication in the Teacher-Pupil Relationship". Procedia- Social and Behavioral Sciences, vol. 180, pp. 543-548, 2015.

R. Fujishin, Creating communication. Exploring and expanding your fundamental communication skills, U.S.A.: Rowman \& Littlefield Publishers, Inc, 2009.

H. Garcia, The power of communication skills to build trust, inspire loyalty, and lead effectively, New Jersey: Pearson Education, Inc, 2012.

S. Iordanidou, P. J. Stamatis, \& L. Valsamidou, "Communication in Education and Education in Media literacy a theoretical and research approach in the field of Preschool Education", in Theory and research methodology issues in Communication in Education, A. Kontakos and P. J. Stamatis, Eds. Athens: Diadrasi, 2020, pp. 209-243.

B. Johnston, A. O'Connor-Ledbetter, K. Barrett, \& K. Pine, Introduction to Public Communication, Indiana State University: Pressbooks.com, 2016.

H. Klinzing, \& B. Aloisio, "Nonverbal competences and Psycho-social dimensions: corelational and experimental studies on the nature of their relationships and on competence-improvement based on the teaching via cooperative research approach", in Nonverbal Communication in Education: Theory and practice, H. G. Klinzing, N. Polemikos, A. Kontakos, \& P. Stamatis, Eds. Athens: Diadrasi, 2014, pp. 219-295.

M. Malikiosi-Loizou, \& E. Sponta, "The impact of education in communication skills in nonverbal interaction behavior of the preschool", in Nonverbal communication. Modern theoretical and research approaches in Greece, N. Polemikos, \& A. Kontakos, Eds. Athens: Ellinika Grammata, 2002, pp. 165-185.

J. C. McCroskey, V. P. Richmond, \& V. E. Bennett, "The relationships of student end-of-class motivation with teacher communication behaviors and instructional outcomes", Communication Education, vol. 55(4), pp. 403-414, 2006.

T. P. Mottet, A. B. Frymier, \& S. A. Beebe, "Theorizing about instructional communication", in Handbook of Instructional Communication, T. P. Mottet, V. P. Richmond, \& J. C. McCroskey, Eds. Boston: Allyn \& Bacon, 2006, pp. 255-285.

C. Mutongi, "Nonverbal Communication: The Part it Plays in Interpersonal Communication", American Journal of Engineering Research, vol. 6 (7), 88-91, 2017.

S. Myers. (2017). Instructional communication. [Online]. Available: https://www.oxfordbibliographies.com/view/document/obo9780199756841/obo-9780199756841-0177.xml

J. Okon, "Role of Nonverbal Communication in Education". Mediterranean Journal of Social Sciences, vol. 2(5), pp. 35-40, 2011

E. Pladevall-Ballester, "Verbal and Nonverbal Teacher Immediacy and Foreign Language Anxiety in an Efl University Course". Porta Linguarum 23, pp. 9-23, 2015.

V. P. Richmond, J. C. McCroskey, \& M. L. Hickson, Nonverbal behavior in interpersonal relations. Boston: Allyn \& Bacon, 2012.

M. Sheybani, "The relationship between EFL Learners' Willingness to Communicate (WTC) and their teacher immediacy attributes: A structural equation modelling”. Cogent Psychology, 6(1), pp. 1-14, 2019.

C. J. Simonds, \& P. J. Cooper, Communication for the classroom teacher, Pearson, Allyn \& Bacon, 2011.

P. J Stamatis, Preschool and Primary Pedagogy. Communication dimensions of the educational process, Athens: Diadrasi, 2015.

Stamatis, P.J., \& Kostoula, V.E. (2021). Nonverbal Immediacy in Teaching Process: A Case Study in Secondary Education.

H. G. Klinzing, N. Polemikos, A. Kontakos, \& P. Stamatis, Eds. Athens: Diadrasi, pp. 321-363, 2014.

J. Velez, \&, J. Cano, "Instructor Verbal and Nonverbal Immediacy and the Relationship with Student Self-efficacy and Task Value Motivation". Journal of Agricultural Education vol. 53(2), pp. 87-98, 2012.

I. Vrettos, Nonverbal behavior of teacher-student. Practice with microteaching, Athens: Self-publishing, 2010.

Q. Zhang, \& D. Sapp, "A Burning Issue in Teaching: the impact of teacher burnout and nonverbal immediacy on student motivation and affective learning". Journal of Communication Studies, vol. 1(2), pp. 152-168, 2008.

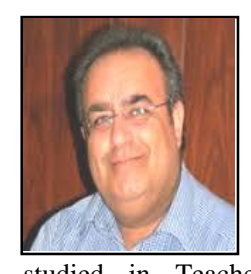

Panagiotis J. Stamatis was born in Rhodes, Greece. He studied the Sciences of Education in Pedagogical Academy of Mytilene (1987), and then he continued his studies in the Dept. of Preschool Education (1992) and in the Dept. of Primary School Education (1995), University of the Aegean, from where he earned BA's in Preschool and Primary Education. After that he studied in Teachers' Training Center "Alexander Delmouzos", University of the Aegean, where he completed a two-year cycle of Further Teaching Training in Primary Education (PGDA). On 2003, in the Department of Sciences of Preschool Education and Educational Design, University of the Aegean, he completed his PhD studies with honors in Pedagogical Communication (putting emphasis on nonverbal communication in preschool education). Since 1989 to 2012 he worked in Primary School Education, reaping a great teaching and administrative experience. He left Primary School Education while he was an Elementary School Teachers' Counselor.

In 2018 he was appointed at the rank of Associate Professor in the field of "Communication in Preschool and Early Primary School Education" in the Dept. of Sciences of Preschool Education and Educational Design, Faculty of Humanities, University of the Aegean which is sited in the island of Rhodes, Greece. He has participated in conferences as delegate and as a member of many scientific and organizing committees, he has participated in educational and research projects and programs, he has published pedagogical books, himself or in collaboration (Stamatis, P. J. $\&$ Nikolaou, E. N. (2020). Communication and Mental Health Promotion in Early Childhood Education. USA, NY: Nova Science Publishers. Stamatis, P. J. \& Nikolaou, E. N. (2018, Eds.). Violent Communication and Bullying in Early Childhood Education. USA, NY: Nova Science Publishers). Also, he has published numerous articles in Greek and international journals, conference proceedings, books, magazines and other printed matters, he is reviewer in Greek and international journals, and he has given lectures in various institutions, clubs and Universities.

Associate Professor Dr. Stamatis is a member of the Greek Pedagogical Association. He has honored for his writings and activities by the Rhodian authorities and institutions, where he is active for many years, as he has been President or/and Member of Municipal Organisms related to Education and Culture. Finally, he has been Member of many Committees, Associations, Libraries or other services regulated by Municipal Authorities or supervised by the Greek Ministry of Education and Religious Affairs.

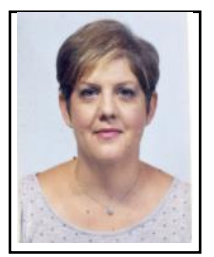

Vasiliki E. Kostoula was born in Rhodes, Greece. She holds a BA from the Faculty of Philosophy, Pedagogy and Psychology, National and Kapodistrian University of Athens (1995) and a MA in Models of Educational Planning and Development, of the Department of Sciences of Preschool Education and Educational Design, University of the Aegean (2016). She is currently working on her $\mathrm{PhD}$ dissertation in the field of verbal and nonverbal communication.

She is a deputy head teacher in an Upper Secondary General School sited in Rhodes island, Greece. She has also been supervising students' projects for five years. She has been a member of school committee of the Panhellenic exams for the last ten years. She has published several papers in educational journals. 